\section{Entrevista com Henry Rousso ${ }^{1}$}

\section{Angélica Müller [*]}

\section{Francine legelski [**]}

[*] Universidade Federal Fluminense - UFF Niterói (RJ) - Brasil.

E-mail: angelicamuller@id.uff.br

ORCID: https://orcid.org/0000-0002-9323-8426

[**] Universidade Federal Fluminense - UFF Niterói (RJ) - Brasil.

E-mail: francineiegelski@hotmail.com

ORCID: https://orcid.org/0000-0001-5026-5048
Resumo: Trata-se de entrevista com o historiador francês Henry Rousso.

Palavras chave: história do tempo presente; usos públicos da história; memória.

\section{Entretien avec Henry Rousso}

Résumé: Entretien avec l'historien français Henry Rousso.

Mots-clé: histoire du temps présent; usages publics de l'histoire; memoire.

\section{Enterview with Henry Rousso}

Abstract: Refers to the enterview with french historian Henry Rousso.

Keywords: history of present time; public uses of the past; memory. 

no Centre National de la Recherche Scientifique (CNRS), Chevalier de l'Ordre national du Mérite et doutor honoris causa pela Universidad Nacional de la Plata (Argentina). Seus trabalhos mais conhecidos têm por tema a Segunda Guerra Mundial e o regime de Vichy. Nos últimos anos, tem se dedicado ao estudo da história da memória coletiva e dos usos do passado, campo que ajudou a construir.

1. Você poderia falar sobre as transformações nas pesquisas de história do tempo presente durante a última década? Como os historiadores escreviam a história do tempo presente e como a escrevem hoje?

Em primeiro lugar, a história do tempo presente se manteve como uma parte importante da disciplina histórica em geral. Ela continua a atrair um número considerável de estudantes e, fato significativo, muitos historiadores vindos de outros períodos também se interessam por ela — por outro lado, existem poucos "contemporaneístas" que fazem história moderna ou medieval. Em seguida, essa história é cada vez mais identificada como uma "história pública", uma forma de conhecimento que se inscreve na esfera pública, e não apenas na esfera universitária. Isso se deve, sem dúvida, à importância política, cultural ou social de certas temáticas, ligadas ao estudo do passado recente: os fenômenos da transição democrática, a saída de conflitos e de ditaduras, as questões da memória, o lugar respectivo das identidades nacionais, locais, étnicas ou religiosas, tantos assuntos que dizem respeito diretamente à escrita da história, particularmente quanto aos usos do passado no presente, que é um dos componentes maiores da atual história do tempo presente. Entre as mudanças, eu destacaria igualmente uma maior atenção dos historiadores à dimensão antropológica dos fenômenos que antes eles estudavam quase exclusivamente enquadrados pela leitura política, econômica ou social. Penso, aqui, nos estudos sobre a violência, em particular nos estudos sobre a violência de guerra, com uma atenção dedicada mais às maneiras de se enfrentar que às causas da guerra, ou ainda uma preocupação crescente com as vítimas civis. Essa abordagem renovou completamente a história da Primeira Guerra Mundial, a história do nazismo e a da Shoah, ${ }^{2}$ ou ainda a das guerras coloniais. Finalmente, uma das evoluções recentes da disciplina em seu conjunto tem menos a ver com a importância concedida a tal ou tal período da história, recente ou antiga, que com a mudança de escala na análise histórica, uma atenção dirigida a uma abordagem mundializada ou conectada. Ela permite vislumbrar uma história que

\footnotetext{
${ }^{2}$ Termo hebraico frequentemente usado para se referir ao Holocausto. [N.T.]
} 
podemos qualificar de "multipolar", ou mesmo limitar os efeitos do eurocentrismo, algo que tentei fazer em minha última obra ao propor a ideia de "mundialização da memória".

2. Você começa La dernière catastrophe 3 (2012) com uma frase dita por François Bédarida quando da organização de um colóquio sobre o regime de Vichy em 1989: "Vocês não viveram esse período, não podem compreender." Ao longo do livro, aprendemos que, com a aparição da história do tempo presente, ocorre também a emergência da testemunha, que é ao mesmo tempo concorrente e cúmplice do historiador na tarefa de escrever a história. Quais são os limites para o trabalho entre os historiadores e os protagonistas da história? E quais são os principais desafios para que o historiador possa manter um olhar distanciado em relação àquilo que é próximo?

A questão da distância em história do tempo presente é ao mesmo tempo banal e central. Banal porque, por definição, diz respeito a todas as ciências sociais que se envolvem com a matéria viva, com a "carne humana", para citar Marc Bloch. Ela diz respeito, de resto, a toda a disciplina histórica: na França, os debates sobre a Revolução Francesa, velha há dois séculos, podem ser tão vivos quanto aqueles sobre a Segunda Guerra Mundial ou sobre a Guerra da Argélia. As paixões em relação ao passado são pouco dependentes do tempo transcorrido: para mim, foi muito mais difícil trabalhar sobre o regime de Vichy em meados dos anos 1990, quando esse período suscitava polêmicas muito vivas no espaço público francês, do que 20 anos antes, em meados dos anos 1970, quando esse assunto ainda era mais ou menos tabu. No entanto, se o historiador dos períodos antigos deve fazer o esforço de neles se projetar para torná-los inteligiveis a seus contemporâneos, o historiador do tempo presente, por sua vez, deve fazer o esforço inverso, colocar a distância seu próprio tempo, separar-se do sentimento de proximidade, notadamente com os atores da história que ele atravessa e interroga. A relação com o testemunho é fundamental aqui, em primeiro lugar porque ele é uma fonte decisiva para os historiadores, um meio de ter acesso a um conhecimento que as fontes escritas nem sempre permitem. É também uma forma de obrigação moral para o historiador do tempo presente permitir que essas testemunhas - quer façam parte das elites, notadamente políticas, quer sejam pessoas comuns em condições ordinárias - se expressem, que elas figurem como atores no relato que vai produzir. Isso não se passa sem conflitos, sobretudo em uma época na qual o lugar da testemunha e, mais ainda, o da vítima adquiriu uma dimensão considerável na sensibilidade pública. Isso coloca de modo definitivo uma questão epistemológica que

${ }_{3}^{3}$ Para a tradução brasileira: ROUSSO, Henry. A última catástrofe: a história, o presente, o contemporâneo. Tradução de Fernando Coelho e Fabrício Coelho. Rio de Janeiro: FGV, 2016. [N.T.] 
reflete meu diálogo com François Bédarida, que foi meu mestre: como encontrar o justo equilíbrio, na escrita da história do tempo presente, entre experiência e conhecimento, entre aquilo que a testemunha pode dizer e transmitir de sua própria experiência vivida e aquilo que o historiador vai construir a partir dos traços de um passado que lhe é, no final das contas, em grande parte estrangeiro. Essa diferença de natureza é fundamental para compreender aquilo que se passa hoje nos conflitos memoriais, ou ainda para compreender por que se continua a opor história e memória, como se uma representasse a razão, e outra, a emoção. Na verdade, a história se alimenta da memória, e o historiador se alimenta da palavra das testemunhas. Quanto à memória coletiva ou individual, ela integra o conhecimento histórico, pois uma testemunha, mesmo se evoca sua própria experiência, também lê livros de história.

3. Em seu último livro, Face au passé (2016), você afirma que a memória se tornou um valor cardeal de nosso tempo, propondo uma leitura das formas de mundialização da memória. Como você vê a especificidade do tempo presente brasileiro, no qual a ditadura militar teve fim em 1985 e uma Comissão Nacional da Verdade foi criada cerca de 30 anos depois, sem, no entanto, ter efeito prático mais importante?

Eu não conheço o suficiente do caso brasileiro para falar, mas o modelo da anistia e do silêncio nitidamente prevaleceu durante muito tempo após a queda da ditadura, antes que a necessidade de verdade sobre a natureza e a amplidão dos crimes cometidos, o desejo de justiça para punir os culpados e a necessidade de um reconhecimento das vítimas se traduzissem na criação da Comissão Nacional da Verdade. Verdade, justiça e reconhecimento, eis o tríptico contemporâneo que caracteriza a maioria das políticas de memória. Em relação a experiências similares de comissões de "verdade e reconciliação", na América Latina ou em outros lugares, parece haver aqui um descompasso [décalage] muito importante entre o fim da ditadura e a tradução de uma vontade política de olhar o passado no rosto. O ensaio de modelo que propus não significa que em toda parte, no mesmo momento, o "dever de memória" se imponha como um novo direito do homem. Ele constitui, no entanto, um horizonte democrático, um elemento importante dos processos de democratização, que evolui em função dos contextos políticos ou culturais próprios a cada país. É nesse sentido que a história da memória, dos usos e das representações do passado, no nível dos discursos e ações políticas tanto quanto no nível das diferentes camadas da sociedade, constitui um campo essencial da história do tempo presente. De um lado, os estudos sobre a memória em parte permitiram fundar essa disciplina, mas a memória constitui também, e ao mesmo tempo, um problema histórico contemporâneo 
de primeira importância que a história do tempo presente deve estudar, como o fazem as outras disciplinas (a sociologia, a ciência política, a antropologia etc.).

\section{Uma história do tempo presente pode ser compreendida como um aspecto de uma perspectiva presentista?}

Na verdade, eu defendo a ideia inversa. A história do tempo presente é, em primeiro lugar, uma maneira de fazer história tout court. Então, tem por objetivo dar uma perspectiva de média ou de longa duração, insistir sobre o caráter mutante de nossa relação com o passado e, frequentemente, relativizar aquilo que parece novo aos contemporâneos ou, ao contrário, mostrar a novidade ali onde acreditávamos ver uma permanência: a situação política atual na França, com a chegada ao poder de Emmanuel Macron, uma figura política nova por sua juventude, sua tomada de poder inesperada ou seu modo de governo, e ao mesmo tempo inscrita em uma tradição, aquela do reformismo, oferece, desse ponto de vista, um caso exemplar. O historiador do tempo presente, como outros, pode também, às vezes, colocar-se em guarda contra essa ideia de que nosso presente, nossos valores - que são, no final das contas, efêmeros - podem reescrever uma história no "bom senso" ou reparar os efeitos de velhos processos que datam de séculos. Recentemente, logo após o atentado de Charlottesville, uma consequência da decisão de retirar de um parque da cidade uma estátua do general Lee, figura emblemática dos supremacistas americanos, uma associação francesa, o Conseil représentatif des associations noires (Cran) [Conselho Representativo das Associações Negras] exigiu que se fizesse o mesmo com as estátuas de Colbert, ministro de Luís XIV e figura emblemática da história da França, que foi também um dos inspiradores do Código Negro, o texto de referência da escravidão. Esse é um exemplo de uma forma de embranquecimento da história e de uma leitura exclusivamente presentista do passado que reduz uma personagem ou um evento histórico exclusivamente à dimensão moral, que só lê o passado pelas grandes obsessões de nosso presente, nesse caso, o antirracismo, conceito que não tem muito sentido se aplicado ao século XVII. A história da memória tal como foi desenvolvida pelos historiadores do tempo presente permite colocar em perspectiva tais reivindicações fundadas exclusivamente sobre emoções identitárias.

\section{Qual é seu próximo projeto editorial?}

Neste exato momento, interesso-me pela questão do ressentimento e da vingança das vítimas de grandes crimes de massa: o genocídio dos armênios, a Shoah e o genocídio dos tútsis em Ruanda. É uma maneira de abordar um aspecto pouco 
conhecido, às vezes tabu, das questões ligadas aos "passados que não passam". A vingança é uma forma de memória longa, uma maneira de perpetuar a lembrança ou de exigir justiça e reparação, mas em modalidades que são, em princípio, banidas das sociedades civilizadas. Ora, esses modos de vingança existiram quase sistematicamente em todas as formas de conflito contemporâneas, e os historiadores prestaram menos atenção a elas que a outras modalidades, por exemplo, as comemorações e os monumentos. É, para mim, também uma maneira de continuar a observar minha época com um olhar crítico e, portanto, não presentista... Após uma repressão sanguinária ou após um genocídio, a reconciliação pacificada, que se tornou o modelo desejável, pelo menos um pouco em todas as partes do mundo, nas saídas da guerra ou de uma ditadura, não é imposta facilmente. Ela é atingida frequentemente com a supressão, mais ou menos bem aceita, do ressentimento legítimo das vítimas, o qual se traduz vez ou outra em manifestações de violência e de vingança contra os carrascos de ontem.

\section{Referência bibliográfica}

ROUSSO, Henry. A última catástrofe: a história, o presente, o contemporâneo. Rio de Janeiro: FGV, 2016. ROUSSO, Henry. Face au passé: essais sur la mémoire contemporaine. Paris: Belin, 2016. 